\title{
Uma abordagem conceitual sobre garantias de representação no gerenciamento da organização de estoques de informação como proposição ético- informacional
}

\author{
Jackson da Silva Medeiros \\ Doutor; Universidade Federal do Rio Grande do Sul (UFGRS), Porto Alegre, RS, Brasil; \\ jackson.medeiros@ufrgs.br
}

\begin{abstract}
Resumo: Este trabalho, de caráter teórico-conceitual, busca destacar o papel ético-informacional do gerenciamento da organização de estoques de informação. Para isso, parte da premissa de que a informação é baseada em significado contextual e está disposta a partir de estoques de informação, os quais nos fazem refletir sobre dilemas morais, principalmente sobre a criação, a organização e o uso das informações disponibilizadas, criando um tensionamento entre processos institucionais e indivíduos. A partir disso, procuramos inferir implicações para o gerenciamento ético da organização de estoques de informação como forma de crítica racional a minimizar problemas de indexação e, por consequência, melhorar a recuperação da informação.
\end{abstract}

Palavras-chave:Gerenciamento da organização de estoques de informação. Ética da informação.Indexação.

\section{Introdução}

O objetivo deste trabalho é trazer a lume delineamentos de pesquisa que possamos desenvolver e colaborar com os estudos de informação, em especial com questões relacionadas à ética da informação e ao gerenciamento da organização de estoques de informação ${ }^{1}$, principalmente em relação às políticas da indexação. Nossa intenção é que, ao apresentar este ensaio, ele sirva como um norte de nosso projeto de investigação, agindo como uma marca da caminhada estipulada a partir dos recortes que são apresentados, sem a pretensão de esgotar os temas aqui propostos.

Nossa abordagem vai na direção de uma compreensão sobre os caminhos que devem ser traçados para que pensemos o gerenciamento da organização de estoques de informação a partir de um posicionamento ético-informacional. Para 
tal, é importante conhecer a informação em essência, desde os aspectos anteriores à sua produção até aspectos posteriores à recuperação, ou seja, passa por compreender suas características políticas, institucionais, profissionais etc., bem como as questões de seleção, aquisição, organização, controle, tecnologia, usuários, entre outros. Isto chamamos de contexto. Assim, devemos partir, filiando-nos a Barreto (2005), da ideia de que a informação atua como estrutura significante, o que a compreende com efetivo potencial informativo com fins sociais.

Se temos em uma ponta a geração, há uma série de instruções que, ao considerarmos como potencialmente informacionais, são portadoras de significado, dependentes de diversos fatores para que efetivamente sejam assimiladas como tal. Essas, a partir do momento em que são apreendidas em suas qualidades, de forma e de substância, atuam como “[...] estruturas simbolicamente significantes com a (in)tensão de gerar conhecimento no indivíduo em seu grupo e na sociedade.” (BARRETO, 2005).

Se há intenção ${ }^{2}$ por parte do produtor de informação que determinado conhecimento seja gerado, disseminado e assimilado, chegamos à conclusão que há elevado grau de responsabilidade nesse processo, uma vez que a informação é distribuída através de determinados canais conhecidos como estoques de informação. Essa responsabilidade atua em vários âmbitos, indo desde a produção até o uso, passando por critérios que baseiam a indexação por parte do profissional responsável pela disseminação da informação, essencialmente, o bibliotecário.

Entendemos que a Ciência da Informação, a partir de sua essência inter e multidisciplinar, requer que seu aparato conceitual seja revisado de forma permanente, uma vez que a disciplina é afetada substancialmente pela evolução da ciência e da tecnologia, fazendo com que suas fronteiras estejam em constante reordenamento, justapondo métodos, teorias e aplicações capazes de prover melhores serviços de informação. Desse modo, as questões éticoinformacionais sofrem com uma conjuntura especial, uma vez que não podem ser relegadas em nenhum momento ou espaço. 
Para tal empreitada, a metodologia utilizada para este trabalho foi, sem precisar períodos, uma análise retrospectiva de materiais bibliográficos que discutem questões relacionadas à ética e à ética da informação, como Capurro (2010), Droit (2012), Fourez (1995), Freire (2010) e Sanchéz Vázquez (1987), bem como questões sobre garantias na representação da informação, como Beghtol (1986; 2002) e Mai (2011). Também foram utilizados materiais sobre gerenciamento e políticas de informação de autores como Fujita (2012) e Nunes (2004).

\section{Problematizando a necessidade de estudos ético-informacionais}

Podemos dizer, com apoio de Edgar Morin (2010, p. 126), que "Os problemas atuais são tão grandes que não temos soluções para eles [...]", mas esses problemaspoderiam ser minimizados a partir da existência de mais trabalhos na temática Ética da informação. Esse ponto pode ser considerado o grande gap que nossa proposição busca, ainda que em parte, ocupar.

Não buscamos uma iniciativa com o intuito de projetar julgamentos éticos/morais, uma vez que caso após caso é necessário que sejam delineados assuntos situacionais/contextuais para cada acontecimento. O que queremos é contribuir para um melhor aproveitamento do saber gerencial, no sentido de “colocar as cartas na mesa" e vislumbrar minimizar danos para o gerenciamento da organização em estoques de informação.

O que seguidamente vivenciamos é a análise de uma conduta que se baseiaem valores referenciais explícitos, já que proceder baseado em princípios morais permite ao profissional fortalecer "A organização em que atua, porquanto que instituiu um padrão comum explícito de avaliação e assegura critérios convergentes de ação.” (VALENTIM, 2004, p. 59). Dessa maneira, há um estabelecimento claro de responsabilidade institucional com o usuário, com a informação e seu estoque, com a profissão e consigo mesmo (GUIMARÃES, 2000).

São nesses quesitos que Guimarães, Milani e Pinho (2008), ao estabelecerem uma revisão da literatura sobre ética em organização do conhecimento, mostram que diversos fatores atuam sobre cada item listado, a 
saber: na questão institucional, a literatura não apresenta valores elencados;em relação à informação e seu estoque, valores como precisão, garantia cultural, exaustividade, consistência, flexibilidade, facilidade de uso, hospitalidade do sistema e atualidade;nos valores ligados à profisssão estão cooperação (credibilidade profissional), a competência para identificar problemas éticos, a transculturalidade na mediação, a objetividade no fornecimento dos serviços e a manutenção da competência profissional;no que se refere ao próprio profissional, são realçados valores de competência profissional, eficiência, confiabilidade, reconhecimento profissional, atualidade e autonomia.

Parece-nos que esses princípios essenciais, e muitos outros que deveriam ser elencados em cada situação, são básicos para o estabelecimento de uma política ético-informacional e estão diretamente ligados ao atendimento de questões relativas aos usuários, situando-os em um sistema ético. Assim sendo, os esforços dos responsáveis pelo gerenciamento da organização de estoques de informação estão direcionados para

[...] assegurar a diversidade de acesso às informações culturais e pessoais, os quais atuam no sentido de projetar, avaliar, dar manutenção e revisar os sistemas de representação, de forma que esses se ajustem aos princípios éticos. É seu papel evitar que os desvios sejam disseminados através do fazer profissional. (GUIMARÃES; PINHO, 2007, p. 5).

Valentim (2004, p. 67) lista quatro polos de estratégias que podem ser adotadas para a solução de possíveis problemas éticos:

a) polo político - optar pela ética; criar e aplicar mecanismos de reforço ético;

b) polo conceitual - definir políticas e procedimentos eticamente consistentes, sustentar valores corporativos claros;

c) polo gerencial: - pensar e agir de forma ética; promover a ética;

d) polo pedagógico - educar para a ética, capacitar as pessoas visando as competências e habilidades éticas. 
Vemos que o quadro proposto por Valentim (2004) não é descritivo de suas proposições, mas atua como um norte no sentido de estabelecer clareza a um processo que, em geral, é opaco e não está preocupado em pensar sobre as ações e sua repercussão para a recuperação da informação na complexidade cultural de uma organização ou de um grupo de pessoas. Disseminar informação, em muitos casos, baseia-se no fornecimento de instrumentos e regras prontas e gerais para o acesso à informação.

Podemos dizer que os valores referentes à organização da informação, embora existentes, não são assumidos de forma clara (GUIMARÃES; PINHO, 2008) e ainda são pouco discutidos. Muitas vezes isso ocorre porque o processo de representação realizado pelo bibliotecário está ligado à sua intuição, e não à análise de questões que, embora essenciais, passam despercebidas. É o que Guimarães e Pinho (2008, p. 81) dizem do ser “[...] consciente não apenas do como, mas também do por quê e do para quê[...]". Compreendemos que parte do processo de assumir uma postura ético-informacional está baseadano gerenciamento da organização de estoques de informação, tema que começamos a tratar a seguir.

\section{Gerenciamento da organização de estoques de informação: políticas de indexação}

Quando mencionamos gerenciamento, situamos um sistema de controle contextual de atividades relacionadas à administração de acervos. Aqui preferimos, como já explicamos, o termo gerenciamento de estoques de informação, e focamos em políticas de indexação, ou seja, diretrizes capazes de nortear a sistematização de rotinas para minimizar problemas de indexação.

Os estudos sobre recuperação da informação em seus estoques têm longa tradição na Biblioteconomia e na Ciência da Informação. A utilização de metadados desempenha papel importante nesse quadro, podendo ser utilizados como elementos de descrição de forma e de conteúdo, sendo este último realizado a partir da extração ou atribuição de termos com base em conceitos expressos nos documentos. A representação da informação é um dos campos de atuação do bibliotecário. 
Para esse fim, de forma geral, são utilizados instrumentos como tesauros, listas de cabeçalho de assunto e, atualmente, ontologias que possibilitam "[...] representar o conhecimento inscrito e promover interação entre usuário e dispositivo." (KOBASHI, 2007, doc. não paginado), ou seja, são processos e produtos que interessam todos os envolvidos no lidar com estoques de informação. No entanto, a “[...] utilização de um desses instrumentos, por si só, é insuficiente para que se alcance a tão almejada boa qualidade da indexação.” (NUNES, 2004, p. 55).

Essa assertiva orienta a necessidade do desenvolvimento de ferramentas que possibilitem gerenciar, através do estabelecimento de políticas, a organização dos estoques de informação, atuando, assim, em um nível macro que possibilite o controle de instâncias que dizem respeito à representação da informação de forma pontual. Nesse sentido, uma política para o gerenciamento da indexação necessita do estabelecimento de requisitos que compreendam determinado contexto e posicionem os instrumentos a partir de uma postura ética na fronteira institucional - a organização e sua identidade - com a necessidade informacional dos seus usuários - indivíduos com desejos, anseios, culturas próprias e diferenciadas entre si.

O estabelecimento de políticas para o gerenciamento da informação advém da necessidade de estabelecimento de um tipo de diretriz que estabeleça parâmetros para as relações entre entidades, no caso entre o usuário e o sistema de informação ${ }^{3}$. Nunes $(2004$, p. 55) alerta para isso ao compreender que a política de indexação age como

[...] diretriz que explicita as escolhas técnicas (por isso política) que a biblioteca faz (e os bibliotecários precisam observar em suas rotinas), considerando fundamentalmente duas variáveis: o seu usuário e o seu acervo. (NUNES, 2004, p. 55).

Ou seja, desenvolver condições e documentos formais que materializem a forma de lidar com processos que são técnicos, mas na sua essência atuam como formas constantes de modificação de estoques mentais, tem o sentido de promover que indexadores diferentes ou o mesmo indexador em tempos e em espaços diferenciados sejam guiados através de diretrizes com vistas a promover 
uma sistematicidade que possibilite minimizar problemas de recuperação da informação.

Strehl (1998, p. 329-330), com base em outros autores, elenca elementos de inconsistência que decorrem da não utilização de diretrizes por um mesmo indexador ou por vários indexadores:

[...] o conteúdo real do documento; a parte desse conteúdo que será suscetível de responder realmente às necessidades (inevitavelmente futuras) dos usuários; os conceitos importantes que devem ser conservados para representar este conteúdo; os descritores definidos para representar esses conceitos. (STREHL, 1998, p. 329-330).

Ora, por se tratar de escolhas técnicas, como destacado por Nunes (2004), a proposição deve ser baseada em critérios efetivos para a consolidação de documentos que relacionem aspectos institucionais e dos usuários, levando em consideração características próprias de suas categorias. Nesse sentido, é uma proposição advinda da administração das unidades de informação com aspectos ligados ao conhecimento teórico, metodológico e prático no que se refere à indexação.

Cabe notar que, embora originada como documento formalizado por parte da gerência da unidade, as escolhas técnicas e teóricas não são uma posição hierárquica rígida no sentido chefe-subordinado. Como em um planejamento estratégico para a unidade, a construção de uma política de indexação deve assumir a responsabilidade de congregar os diversos setores, encaminhando formas de melhor conhecer o sistema de informação em todos os seus aspectos e proporcionar melhor acesso à informação.

A conceituação abaixo é esclarecedora:

A política de indexação não deve ser vista como uma lista de procedimentos a serem seguidos, e sim conjunto de decisões que esclareçam os interesses e objetivos de um sistema de informação e, particularmente, do sistema de recuperação da informação. A política decide não só sobre a consistência dos procedimentos de indexação em relação aos efeitos que se necessita obter na recuperação mas, principalmente, sobre a delimitação de cobertura temática em níveis qualitativos e quantitativos tendo em vista os domínios de assuntos e as demandas dos usuários. (FUJITA, 2012, p. 17). 
Entendemos que a citação acima mostra a complexidade do tema e que as proposições explícitas em diretrizes de uma política devem ser oportunas para a relação que se estabelece entre usuário e sistema de informação. $\mathrm{O}$ primeiro, indivíduo constituído por sua subjetividade, regido por leis e por vontades, estabelece buscas a partir de seu aparato cultural, sua linguagem, seu modo de pensar, suas conexões cerebrais. Por outro lado, o sistema atua a partir dos estoques de informação com conteúdo em linguagem natural e com sua representação,ou, em muitos casos, realizada a partir de linguagens documentárias (artificiais) que devem, ao mesmo tempo, suprir as necessidades informacionais dos indivíduos e se orientar por regras institucionais.

Podemos pensar, de acordo com Fujita $(2012)^{4}$, sobre a existência de duas vertentes sob as quais o gerenciamento da organização de estoques de informação pode ser visto: o plano organizacional e o plano técnico ${ }^{5}$. No primeiro estão relacionados os aspectos referentes à instituição à qual se aplica a política, devendo ser observada a clientela existente a partir de preceitos já estipulados pela organização, bem como os recursos financeiros, materiais e humanos. No segundo estão elementos como cobertura de assuntos, seleção e aquisição de documentos, estratégia de busca, tempo de resposta do sistema, forma de saída e avaliação do sistema, além da indexação propriamente dita. Esta é afetada por quesitos como exaustividade, especificidade, escolha da linguagem, revocação e precisão.

Nesse sentido, parece-nos que as palavras de Fujita (2012) são, ao mesmo tempo, sintetizadoras da necessidade de construção de instrumentos que estipulem diretrizes para o gerenciamento da organização de estoques de informação e explicitam a complexidade do assunto:

[...] a Indexação necessita mais do que a definição do processo de indexar e sua natureza, necessita do entendimento do contexto de gestão do sistema de recuperação da informação composto por todos os requisitos - pessoas, comunidade usuária, domínios de assuntos, infraestrutura física e material e funcionamento como sistema de informação - para a definição de princípios, métodos e orientações quanto às características da indexação e efeitos na recuperação. (FUJITA, 2012, p. 13). 
Podemos dizer, em suma e com base nos autores citados, que uma política de indexação atua como um tipo de decisão administrativa estratégica que aponta aportes teóricos, metodológicos e práticos com vistas à otimização de serviços e racionalização de processos em sistemas de recuperação da informação, tendo sua execução baseada em escolhas técnicas com fins administrativos, por isto é baseada em uma cultura organizacional, orientando o trabalho dos diferentes indexadores, visando a padronização da representação da informação através da minimização da interferência da subjetividade dos profissionais envolvidos neste trabalho, fazendo jus ao papel de socialização do conhecimento.

Nossa conceituação de política de indexação como instrumento de gerenciamento da organização de estoques de informação faz com que pensemos em fatores que possam ser considerados intervenientes no processo de construção desse produto. Compreendemos, assim, que aspectos éticoinformacionais devem ser pensados constantemente para a elaboração dessas ferramentas, possibilitando atuar na diversidade e complexidade que envolve a questão institucional, de estoque de informação e de usuários.

Se entendermos que

"[...] um sistema de armazenagem e recuperação da informação que possui finalidades e objetivos e abriga condições em seu ambiente quanto à natureza da informação produzida e solicitada, bem como caraterísticas da comunidade de usuários [...]" (FUJITA, 2012, p. 22),

para a efetivação de uma proposta ético-informacional deve ser levada em consideração a análise de caso a caso, já que os procedimentos de análise ética são baseados em tempos e em espaços específicos, não cabendo uma análise descontextualizada.

\section{Caminhos a delinear para uma proposição ético-informacional ${ }^{6}$}

Quando falamos de ética, devemos situar, à luz de Fourez (1995), sua ligação àquilo que é desejável em um contexto histórico e social, a partir do que os indivíduos consideram como valores, ideologias, crenças etc. Ou seja, há uma ideia de que o comportamento, um modo de ver e lidar com situações diversas, 


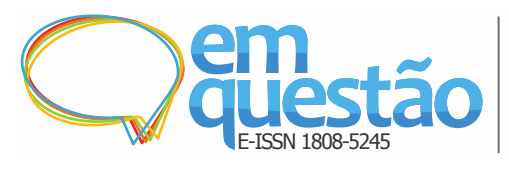

Uma abordagem conceitual sobre garantias de representação no gerenciamento da organização de estoques de informação como proposição éticoinformacional

Jackson da Silva Medeiros

baseia-se em pontos de vista que nunca são neutros. Analisando pela ótica do comportamento é possível dizer que existem comportamentos melhores e piores. Isso ocorre porque

[...] na vida real, defrontamo-nos com problemas práticos [...] dos quais ninguém pode eximir-se. E, para resolvê-los, os indivíduos recorrem a normas, cumprem determinados atos, formulam juízos, e às vezes, se servem de determinados argumentos ou razões para justificar a decisão adotada ou os passos dados. (SANCHÉZ VÁZQUEZ, 1987, p. 7).

Entendendo por ética uma "[...] teoria ou ciência do comportamento moral dos homens em sociedade. Ou seja, é ciência de uma forma específica de comportamento humano [...]" (SÁNCHEZ VÁSQUEZ, 1987, p. 12), extrapolase o caráter científico de abordagem universal e de busca por verdade. O que propomos é a descrição de conceitos, teorias, hipóteses etc. que permitam explicar a realidade moral de forma sistemática, metódica e comprovável.

Ao compreender a razão dos acontecimentos, ou seja, “[...] conceber por razão aquilo que, num quadro discursivo, explica uma ação." (SILVA FILHO, 2009, p. 9), exercitarmos a capacidade de sistematização dos acontecimentos da realidade humana e da sua relação com sistemas de informação a partir de escolhas contextuais. $\mathrm{O}$ autor trata assim da ideia proposta:

[...] uma ação moral, nesta perspectiva, não apenas se é uma 'boa ação', mas se é expressão de uma decisão livre e racional: se numa alternativa posso julgar que a ação A é preferível, é mais justa do que a ação B, logo ajo racionalmente se faço A, pois, na ordem das razões, eu não poderia fazer outra coisa senão A. Se o que eu faço pode ser reconhecido como algo nobre ou reprovável, isto é outro problema: isto está associado a 'seguir ou não uma lei'. Se A era preferível a B, se eu tinha razões para agir como em $\mathrm{A}$, mesmo que isto infrinja uma lei, A permanece sendo uma ação moral e, como tal, posso ser inclusive punido por tal. (SILVA FILHO, 2005, p. $88)$.

Pensando o mundo contemporâneo, sempre conectado e severamente carregado de informação, parece claro notar que os avanços da tecnologia de comunicação tendem a nos colocar em frente a questões nem sempre claras, 
aonde as respostas podem não ser únicas, uma vez que a moral de uma comunidade pode não ser compartilhada por outra (DROIT, 2012). Assim, trabalhar a ética em contexto informacional permite pensar os atos diretos e indiretos das entidades envolvidas no processo de desenvolvimento de políticas que gerenciem a organização de um determinado estoque de informação.

Isso adquire ainda maior amplitude se considerarmos que os estoques de informação são, por conceito, estáticos, e sua efetiva consolidação como portadores de informação se dá na sua interação com humanos. Assim, como observamos, estamos diante de novos problemas morais e, por consequência, éticos que estão refletidos em diversos aspectos do gerenciamento.

Droit (2012), neste sentido, também mostra preocupação sobre os aspectos éticos relacionados aos novos aparatos tecnológicos aos quais os indivíduos se relacionam, já que, segundo o autor, nos idos dos séculos XVIII e XIX havia a crença de que o avanço no conhecimento garantiria progresso ético, até se demostrar a importância de entender problemas relacionados a esses artefatos.

Desta forma é importante considerar que a ética da informação nos é interessante quando se percebe que os

[...] sistemas e tecnologia da informação são fontes de novos problemas morais[...] [oriundos dos] dilemas deônticos ou conflitos morais que surgem na interação entre os seres humanos e as tecnologias e sistemas de comunicação e de informação a fim de refletir e, sobretudo, disciplinar a criação, a organização e o uso das informações. (FREIRE, 2010, p. 7).

Nesse contexto é relevante perceber que o impacto das tecnologias da informação e da comunicação influenciam a sociedade como um todo, tendo efeito para além dos profissionais que lidam com esses aparatos:

[...] a revolução digital também tem uma profunda influência sobre as normas, princípios e valores que estão na base da vida social as quaisa moral ou o ethos cultural de toda sociedade humana. Quando há mudanças tecnológicas e culturais que afetam particularmente as estruturas, sistemas, instituições e regras de informação e comunicação de uma sociedade são produzidos diferentes tipos de crises e 
questionamentos no ethosque suporta as relações sociais, cujo o motor é a comunicação. Este ethos da comunicação é, em parte, codificado na forma de leis nacionais assim como acordos e declarações internacionais com diferentes tipos de obrigatoriedade, ratificação legal e fundamentação teórica. ${ }^{7}$ (CAPURRO, 2010, p. 11, tradução nossa).

Compreender as questões éticas que envolvem a informação na relação com os seres humanos permite que se explique e/ou justifique o agir de determinado grupo perante determinada situação, além de fornecer amparo na resolução de dilemas oriundos da relação existente entre seres humanos e tecnologias, bem como da ligação entre os próprios indivíduos e as organizações a que estão ligados. Isso deve ser refletido no gerenciamento da organização de estoques de informação, abrindo espaço para que os instrumentos sejam suportados por procedimentos morais, como as garantias.

\section{Garantias como preceitos ético-informacionais}

Beghtol (1986, p. 110-111) define de forma clara o que vem a ser a garantia utilizada na construção de sistemas de organização de estoques de informação:

[...] a garantia de um sistema de classificação pode ser pensada como a autoridade que uma classificação invoca primeiramente para justificar e subsequentemente para verificar decisões sobre que classes/conceitos incluir no sistema, em qual ordem classes/conceitos devem aparecer nos esquemas, em quais unidades classes/conceitos são divididas, quão longe a subdivisão deve proceder, quando e onde a síntese está disponível, bem como se a ordem de citação é estática ou variável, além de questões similares. Garantias cobrem pressupostos e decisões conscientes e inconscientes sobre que tipos e quais unidades de análise são apropriadas para incorporar e para carregar significado ou uso de uma classe para o classificador, o qual deve interpretar tanto o documento quanto o sistema de classificação com a finalidade de classificar documentos pelos significados dos dispositivos sintáticos. ${ }^{8}$ (BEGHTOL, 1986, p. 110-111, tradução nossa).

Tomando em consideração que a construção de linguagens de indexação é baseada em um corpus discursivo, o conjunto de expressões que constituem esse corpus está posto a partir da garantia literária e da garantia de uso. Lancaster (1987) sintetiza a garantia literária como sendo as expressões 
utilizadas a partir da reconhecida literatura. No que se refere à garantia de uso, a indexação deve ser realizada de acordo com as expressões utilizadas para recuperação da informação. De forma auxiliar, podemos considerar que a garantia estrutural possibilita que expressões não utilizadas em buscas e não constantes na literatura sejam utilizadas com a finalidade de prover uma estrutura coerente e lógica ao vocabulário construído, sendo selecionadas de forma top-down.

Podemos tomar como contraponto a pesquisa que usuários comumente realizam em sistemas de recuperação de informação, uma vez que as consultas, em geral, não necessariamente são executadas por termos de utilização dos especialistas e/ou dos autores dos trabalhos. Isso faz com que outros tipos de garantias devam ser estudadas, desenvolvidas e empregadas, motivadas pela necessidade de lidar com aspectos que tomam por base a postura dos usuários, bem como os avanços científicos e tecnológicos, como a garantia científica/filosófica, a garantia educacional, a garantia cultural (BEGHTOL, 1986) e a garantia autopoiética (MAI, 2011).

A garantia científica/filosófica advém de um processo no qual se tenta buscar características quase positivas da ciência a partir da estabilidade e do consenso que ali é pressuposto, ou seja, parte da ideia de uma consolidação de equilíbrio das noções empregadas dentro de um campo. Embora a garantia científica/filosófica possa ser considerada parecida com a garantia literária, uma vez que está baseada na literatura, ela se difere na necessidade de compreender uma reflexão do pensar histórico (BEGHTOL, 1986).

A garantia educacional está fortemente ligada à garantia científica/filosófica, mas também está relacionada às práticas educacionais das instituições. Este dispositivo proporcionou às bibliotecas uma classificação de acervos relativamente permanente e respeitável, correspondendo ao que se pode enxergar como um pensamento consensual das comunidades científicas e educacionais (BEGHTOL, 1986).

A garantia cultural pode ser conceituada, segundo Beghtol (1986), como a análise do que é realizado fora do âmbito acadêmico - complementando as garantias literária e científica, por exemplo -, atentando para instrumentos de 
uso rotineiro de pesquisadores, como periódicos em vez de livros, a complexidade que envolve a imbricação de disciplinas e o aparato tecnológico utilizado. Ou seja, parte do contexto cultural/social a que o indivíduo está colocado, uma vez que há uma "[...] multiplicidade de culturas que compõem indivíduos com diferentes atitudes em relação à informação e ao conhecimento [...]."9 (BEGHTOL, 2002, p. 511, tradução nossa).

Para Mai (2011), a autoridade máxima que deve ser respeitada quando da criação de um sistema de recuperação da informação é o usuário. Assim sendo, em sistemas baseados em ambientes colaborativos na web, com vistas à organização da informação, são os partícipes que definem os termos utilizados na representação, fazendo que, com base na cooperação entre os usuários, emerja a autoridade para designação da representação. A isso Mai (2011, p. 119, tradução nossa) atribui o nome de garantia autopoiética, dizendo que “[...] os usuários do sistema de uma forma auto-referencial estabelecem os termos e as classes que devem ser incluídas no sistema e a autoridade do sistema emerge da sua utilização [...]." ${ }^{.10}$.

Tomando essas ideias, fazemos coro à fala de Mai (2011, p. 119):

A mudança do profissionalismo para todos [...] requer não apenas que consideremos as fundamentações conceituais de atividades para cultivar como chaves sólidas e adaptadas para este novo ambiente, mas também para projetar sistemas que verdadeiramente facilitem a criação de ordem no universo do conhecimento de uma forma responsável, democrática e significativa. ${ }^{11}$ (MAI, 2011, p. 119, tradução nossa).

É interessante notar que a relação entre garantias e o gerenciamento da organização de estoques de informação é um processo cíclico, no qual os aspectos ético-informacionais iniciam o sistema e também são, em certa medida, sua finalidade. Isso ocorre porque, em todo processo de gerenciamento de um sistema de informação, a preocupação com o usuário deve se dar a partir do acesso igualitário e fora de qualquer tipo de discriminação e/ou cerceamento, atribuindo às garantias (literária, de uso, científica/filosófica, educacional, cultural e autopoiética) papel determinante para que se estabeleça o gerenciamento ético-informacional da organização de estoques de informação. 


\section{Discussão para considerações que não cessam}

Kevin McGarry, no livro O contexto dinâmico da informação (1999), alerta para algo que está relacionado à construção temporal e de ponto de vista da cultura. $\mathrm{O}$ autor lembra, em tom de exemplo, que a classificação proposta pela Classificação Decimal de Dewey (CDD) apresenta a classe "religião" ligada ao fator contextual de construção do instrumento, isto é, à cultura eurocêntrica. Assim, para Dewey, religiões que não sejam cristãs são classificadas como "outras religiões". E encerra dizendo: "As classificações do conhecimento, como programas de cursos universitários, refletem os valores culturais do seu tempo, e, de fato, os valores das culturas dominantes." (MCGARRY, 1999, p. 154).

Podemos entender que esse processo é baseado no indivíduo produtor e na produção, além de como um receptor é capaz de decodificar aquilo que recebe como mensagem/informação. Isso implica em eventos que dizem respeito ao contexto em que estão postos a partir do produtor e do receptor, fazendo com que se perceba a posição de cada ator em um sistema que sofre diversas influências sociais, econômicas, políticas, institucionais, culturais etc.

Ora, perceber que indivíduos diferentes têm, por óbvio, processos de subjetivação diferenciados e que são atravessados por elementos de uma sociedade, faz com que haja um importante componente ético colocado em pauta. Ou seja, a partir de uma visão de que o indivíduo se constitui como pessoa através de sua interação com a sociedade, é compreensível que sua relação ética e moral com essa seja um item preocupante. O indivíduo atua pela sua razão; o indivíduo não pode, a partir de uma análise ética, opor sua razão à sociedade de forma brutal e sem pensar no próximo e seu conglomerado (sociedade).

Temos, desse modo, plena consciência de que estamos iniciando, ou melhor, projetando o início de um trajeto de uma pesquisa que vislumbramos como de importância ímpar para compreender questões epistemológicas dos estudos de informação. Entendemos que dentre essas questões está colocada a perspectiva de análise ética da informação e o impacto disso na construção e 
disseminação do conhecimento, prática que gera cada vez mais produções, disseminações e mais conhecimento, retroalimentando um processo contínuo e interminável.

É importante ressaltar dois pontos: (i) a importância dedefinição de políticas de gerenciamento da informação em estoques de informação e (ii) a escassa literatura sobre a temática. O primeiro é ponto urgente em unidades que lidam com estoques de informação, no intuito de minimizar problemas com relação à indexação de materiais; o segundo ponto, já mencionado por diversos autores, parece manter um quadro praticamente inalterado ao longo dos anos, uma vez que a prática não se institucionaliza; o quadro teórico é reflexo desse processo e vice-versa.

Há, sem dúvidas, desafios a serem ultrapassados já na organização dos estoques de informação, sempre buscando melhora nos sistemas de representação da informação e do conhecimento científico. No entanto, há de se estabelecer princípios que possam fazer valer uma premissa metaorganizacional, ou seja, que tornem possível estruturar, sistematizar um sistema teóricometodológico-conceitual-prático que envolva a organização/representação. E esse sistema deve ser capaz de lidar com questões que vão de e ao encontro de interesses diversos.

Temos consciência que o estabelecimento de políticas não garante a neutralidade de um sistema de informação, mas é importante que isso seja uma busca constante. Assim, se tornará uma busca pela minimização de procedimentos que podem acarretar problemas no gerenciamento da organização de estoques de informação e, por conseguinte, na recuperação da informação, primando por preceitos éticos/morais no sistema.

Ou seja, estamos diante de uma análise que envolve comportamento a partir de um ponto de vista, em uma posição que nunca é neutra. E isso é culturalmente colocado a partir de questões ligadas a tempos e a espaços diferenciados, fazendo com que seja possível a explicação de questões morais de forma sistemática, sem tentar buscar universais recomendáveis ou que possam refletir o "desejo ideal” como padrão de comportamento. 
Assim sendo, pelo exposto, podemos dizer que ao perceber, compreender e anotar princípios éticos para nortear os processos de construção de sistemas de gerenciamento da organização de estoques de informação, não se está tomando por distante ou ausente a disciplina às estruturas previamente estabelecidas, mas, sim, estabelecendo critérios que permitam negociar valores que devem estar presentes tanto no sistema institucional quanto nos indivíduos.

Como toda escolha é um tipo de atribuição de valor, deve-se levar em consideração que este valor está baseado em um sistema de referências, as quais são, por natureza, muitas e complexas. Nesse sentido, o certo e o errado, o bem e o mal, são seleções que sempre passam por fatores de complicada escolha intelectual e de vida. Compreender que as escolhas devem ser baseadas em critérios racionais, e não em valores emocionais e/ou efêmeros, traz credibilidade e posicionamento centrado em objetivos concretos ao sistema de informação.

\section{Referências}

BARRETO, A. A. A estrutura do texto e a transferência da informação. DataGramaZero, Rio de Janeiro,v. 6, n. 3, jun. 2005. Disponível em: <http://www.dgz.org.br/jun05/Art_01.htm>. Acesso em: 15 ago. 2015.

BEGHTOL, C. A proposed ethical warrant for global knowledge representation and organization systems. Journal of Documentation,Bingley, v. 58, n. 5, p. 507-532, 2002.

BEGHTOL, C. Semantic validity: concepts of warrant in bibliographic classifications systems. Library Resources \& Technical Services, Chicago, v. 30, n. 2, p. 109-125, abr./jun. 1986.

CAPURRO, R. Desafíos teóricos y práticos de la ética intercultural de la información. In: FREIRE, G. H. A. (Org.). Ética da informação: conceitos, abordagens, aplicações. João Pessoa: Ideia, 2010. p. 11-51

DROIT, R.P. Ética: uma primeira conversa. São Paulo: Martins Fontes, 2012.

FOUREZ, G. A construção das ciências: introdução à filosofia e à ética das ciências. São Paulo: UNESP, 1995. 
FREIRE, G. H. Sobre a ética da informação. In: FREIRE, G. H. (Org.). Ética da informação: conceitos, abordagens, aplicações. João Pessoa: Ideia, 2010. p. 510

FUJITA, M. S. L. A política de indexação para representação e recuperação da informação. In: GIL LEIVA, I.; FUJITA, M. S. L. (Ed.). Política de indexação. São Paulo: Cultura Acadêmica; 2012. p. 17-28

GUIMARÃES, J. A. C. O profissional da informação sob o prisma de sua formação. In: VALENTIM, M. L. P. (Org.). Profissionais da informação: formação e atuação profissional. São Paulo: Polis, 2000.

GUIMARÃES, J. A. C.; MILANI, S. O.; PINHO, F. A. Aspectos éticos em Organização e Representação do Conhecimento (ORC): uma análise preliminar de valores e problemas a partir da literatura internacional na área. Encontros Bibli, Florianópolis, n. 25, 2008. Disponível em: $<$ https://periodicos.ufsc.br/index.php/eb/article/view/15182924.2008v13n25p124/883>. Acesso em: 14 ago. 2015.

GUIMARÃES, J. A. C.; PINHO, F. A. Aspectos éticos em organização e representação do conhecimento (O.R.C.). In: FUJITA, M. S. L.; MARTELETO, R. M.; LARA, M. L. G. A dimensão epistemológica da Ciência da Informação e suas interfaces técnicas, políticas e institucionais nos processos de produção, acesso e disseminação da informação. São Paulo: Cultura Acadêmica, 2008. p. 67-85

GUIMARÃES, J. A. C.; PINHO, F. A. Desafios da representação do conhecimento: abordagem ética. Informação \& Informação,Londrina, v. 12, n. 1, jan./jun. 2007. Disponível em:

<http://www.uel.br/revistas/uel/index.php/informacao/article/view/1753/1500>. Acesso em: 14 jul. 2015.

KOBASHI, N. Y. Fundamentos semânticos e pragmáticos da construção de instrumentos de representação de informação. DataGramaZero, Rio de Janeiro,v. 8, n. 6, dez. 2007. Disponível em: <http://www.dgz.org.br/dez07/Art_01.htm>. Acesso em: 12 ago. 2015.

LANCASTER, F. W. Construção e uso de tesauros: curso condensado. Brasília: IBICT, 1987.

MAI, J.-E. Folksonomies and the new order: authority in the digital disorder. Knowledge Organization, Wurzburg, v. 38, n. 2, p. 114-122, 2011.

MCGARRY, K. O contexto dinâmico da informação. Brasília: Briquet de Lemos, 1999.

MORIN, E. Teses sobre a ciência e a ética. In: MORIN, E. Ciência com consciência. 14. ed. Rio de Janeiro: Bertrand Brasil, 2010. 
NUNES, C. O. I. Algumas considerações acerca da ausência de políticas de indexação em bibliotecas brasileiras. Biblos, Rio Grande, v. 16, p. 55-61, 2004.

SÁNCHEZ VÁSQUEZ, A.Ética. 10. ed. Rio de Janeiro: Civilização Brasileira, 1987.

SILVA FILHO, W. J. Considerações pós-éticas sobre a ação e a racionalidade. In: TEIXEIRA, A. (Org.). Especificidades da ética na Psicanálise. Salvador: Associação Científica Campo Psicanalítico, 2005. p. 86-97

SILVA FILHO, W. J. Ética sem fundamentos. In: GOMES, H. F.; BOTTENTUIT, A. M.; OLIVEIRA, M. O. E. (Org.). A ética na sociedade, na área da informação e da atuação profissional: o olhar da Filosofia, da Sociologia, da Ciência da Informação e da formação e do exercício profissional do Bibliotecário no Brasil. Brasília: Conselho Federal de Biblioteconomia, 2009. p. 9-29

STREHL, L. Avaliação da consistência da indexação realizada em uma biblioteca universitária de artes. Ciência da Informação, Brasília, v. 27, n. 3, p. 329-335, set./dez. 1998. Disponível em:

<http://www.scielo.br/pdf/ci/v27n3/27n3a11.pdf>. Acesso em: 27 jul. 2015.

VALENTIM, M. L. P. Ética profissional na área de Ciência da Informação. In: VALENTIM, M. L. P. (Org.). Atuação profissional na área de informação. São Paulo: Polis, 2004.

\section{A conceptual approach to representation guarantees in} managing the organization of stocks of information as anethicalinformational proposition

\footnotetext{
Abstract: This theoretical-conceptual work seeks to highlight the ethical and informational role of managing the organization of stocks of information. In order to do so, it starts from the premisethat information is based on contextual meaning and is stored in stocks of information, which make us reflect on moral dilemmas, especially on the creation, organization and use of the information, creating a tension between institutional processes and individuals. Based on that, we try to infer implications for the ethical management of the organization of stocks of information as a way of rational criticism to minimize indexing problems and to improve information retrieval.
} 
Keywords: Managementof the organization of stocks of information.

Information ethics. Indexing.

Recebido em 14/10/2015

Aceito em 20/12/2015

${ }^{1}$ Os estoques de informação são conceituados por Barreto (2000) da seguinte maneira: “[...] toda a reunião de estruturas de informação. Estoques de informação representam, assim, um conjunto de itens de informação organizados (ou não), segundo um critério técnico, dos instrumentos de gestão da informação e com conteúdo que seja de interesse de uma comunidade de receptores. As estruturas de informação que se agregam nos estoques podem estar em diferentes níveis de completeza em relação a uma mesma peça de informação: ter o formato só da referência bibliográfica, ou do título, do resumo, indicadores por palavra-chave, ou o texto completo". Utilizamos, neste sentido, o conceito de estoques de informação, como abordado por Barreto (2000), pois compreendemos que ao extrapolarmos uma conceituação tradicional dentro da Biblioteconomia e da Ciência da Informação, como um acervo ou mesmo uma biblioteca, compreendemos um estado de emancipação das atividades biblioteconômicas à difusão da informação em formato físico. Ou seja, estamos nos impulsionando para abarcar uma gama de possibilidades que vão além do mundo físico, compreendendo quaisquer outros âmbitos existentes. Para além disso, a noção de estoques de informação possibilita que se compreenda, ou melhor, que se projete compreensão, sobre a ideia de estruturas de informação. Estas, compreendemos, designam todo um sistema que diz respeito à materialidade documental, ou seja, as inscrições que materializam determinado conteúdo informacional derivado de conhecimento. Assim sendo, compreende desde a estrutura linguística cognoscível e a materialização do conhecimento do produtor até o receptor - fluxo extremo e o chamado fluxo informacional, correspondente ao sistema de armazenagem e recuperação da informação - fluxo interno - e ao sistema (BARRETO, 2001).

${ }^{2}$ Retiramos a forma apresentada por Barreto - "i(n)tensão" - para apresentar uma ideia clara de nossa própria intenção neste trabalho.

${ }^{3}$ Entendemos, para este trabalho, sistema de informação como um conceito genérico, estabelecido a partir de todo e qualquer ator que possa interferir em um estoque de informação, ou seja, desde o sistema mental de um indivíduo produtor de informação até a sua reutilização por parte de um usuário.

${ }^{4}$ Fujita toma por base o trabalho de Carneiro (1986), Diretrizes para uma política de indexação.

${ }^{5} \mathrm{~A}$ autora nomeia os planos, respectivamente, como plano horizontal de gestão e como plano vertical de organização e representação do conhecimento.

${ }^{6}$ Parte dessa seção foi reestruturada a partir da tese de doutoramento do autor.

${ }^{7}$ No original: "[...] la revolución digital tiene también una profunda influencia en las normas, principios y valores que subyacen a la vida social las cuales constituyen la moral o ethos cultural de toda sociedad humana. Cuando tienen lugar cambios tecnológico-culturales que atañen en particular a las estructuras, sistemas, instituciones y normas de información y comunicación de una sociedad se producen diversos tipos de crisis y cuestionamientos en el ethos que sustenta las relaciones sociales, cuyo motor es justamente la comunicación. Dicho ethos comunicacional se encuentra en parte codificado en forma de leyes nacionales así como de acuerdos y declaraciones internacionales con distinto tipo de obligatoriedad, ratificación legal y fundamentación teórica."

${ }^{8}$ No original: "[...] he warrant of a classification system can be thought of as the authority a classification invokes first to justify and subsequently to verify decisions about what classes/concepts to include in the system, in what order classes/concepts should appear in the schedules, what units classes/concepts are divided into, how far subdivision should proceed, how much and where synthesis is available, whether citation order is static or variable and similar questions. Warrant covers conscious or unconscious assumptions and decisions about what kinds and what units of analysis are appropriate to embody and to carry the meaning or use of a class to the classifier, who must interpret both the document and the classification system in order to classify the documents by means of syntactic devices.”. 
${ }^{9}$ No original: "[...] multiplicity of cultures that are made up of individuals with varying attitudes towards information and knowledge [...].".

${ }^{10}$ No original: "[...] users of the system in a self-referential manner establish the terms and classes to be included in the system and the authority of the system emerges from its use [...].".

${ }^{11}$ No original: "The shift from professionalism to everyone [...] requires not only that we consider the conceptual foundational of the activities to ground them solidly and adapt key concepts to this new environment, but also that we design systems that actually do facilitate the creation of order in the universe of knowledge in a responsible, democratic, and meaningful manner [...].". 